\title{
Pseudoepitheliomatous, Keratotic, and Micaceous Balanitis
}

\author{
Sweta Subhadarshani, ${ }^{1}$ Vishal Gupta, ${ }^{1}$ Jayati Sarangi, ${ }^{2}$ Shipra Agarwal, ${ }^{1}$ Kaushal K. Verma ${ }^{1}$
}

\begin{abstract}
1 Department of Dermatology and Venereology, All India Institute of Medical Sciences, New Delhi, India
2 Department of Pathology, All India Institute of Medical Sciences, New Delhi, India
\end{abstract}

Key words: balanitis, pseudoepitheliomatous, keratotic, squamous cell carcinoma, glans

Citation: Subhadarshani S, Gupta V, Sarangi J, Agarwal S, Verma KK. Pseudoepitheliomatous, keratotic, and micaceous balanitis. Dermatol Pract Concept. 2020;10(1):e2020012. DOI: https://doi.org/10.5826/dpc.1001a12

Accepted: September 9, 2019; Published: December 31, 2019

Copyright: (92019 Subhadarshani et al. This is an open-access article distributed under the terms of the Creative Commons Attribution License, which permits unrestricted use, distribution, and reproduction in any medium, provided the original author and source are credited.

Funding: None.

Competing interests: The authors have no conflicts of interest to disclose.

Authorship: All authors have contributed significantly to this publication.

Corresponding author: Kaushal K. Verma, MD, Department of Dermatology and Venereology, All India Institute of Medical Sciences, Ansari Nagar, New Delhi 110049, India. Email: prokverma@hotmail.com

\section{Introduction}

Pseudoepitheliomatous, keratotic, and micaceous balanitis (PEKMB) is a genital disease of uncertain malignant potential that warrants close clinical observation, as it can rarely evolve into squamous cell carcinoma or verrucous carcinoma.

\section{Case Presentation}

A 46-year-old man presented with complaints of scaling and erosion over the glans for the preceding 5 years. He had undergone circumcision 12 years earlier, when he noticed depigmentation over the glans; a few years later, thick, scaly crust developed over the glans. He had no history of high-risk sexual behavior. The patient had previously been treated with topical steroids, emollients, and calcineurin inhibitors without much improvement. On examination, there was hypopigmentation and sclerosis of the glans with localized, thick, yellowish, nail-like keratotic scaling along with underlying induration and superficial erythematous erosions (Figure 1). There was no associated lymphadenopathy, and systemic examination was within normal limits. A skin biopsy from scaly indurated plaque showed hyperkeratosis, parakeratosis,

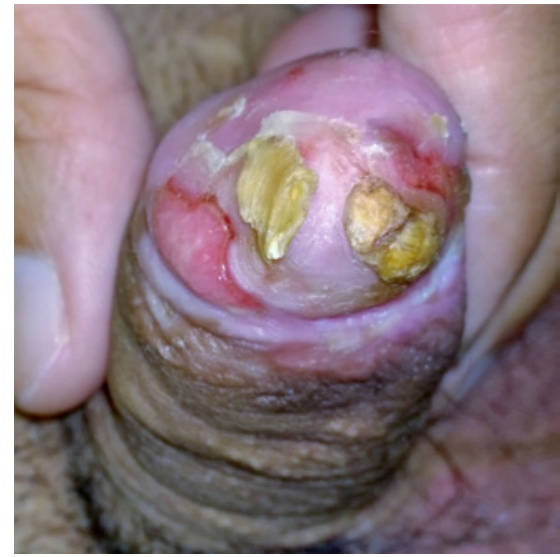

Figure 1. Clinical photograph showing scaling and erosion on the glans.

and acanthosis with dysplastic changes limited to lower layers of epidermis along with a few mitotic figures and an essentially normal dermis (Figure 2). A diagnosis of PEKMB was made. The patient was treated with topical 5-fluorouracil, once daily application over scaly and indurated areas, and he was followed up monthly. However, after 4 months of treatment there was a residual area of persistent induration, a biopsy of which showed moderately differentiated squamous cell carcinoma with areas of necrosis. There was no lymphovascular invasion or distant metastases. A final diagnosis of 
Figure 2. Histopathology $(\mathrm{H} \& \mathrm{E}, \times 4)$ showing hyperkeratosis, parakeratosis, and acanthosis with dysplastic changes limited to lower layers of epidermis along with a few mitotic figures and an essentially normal dermis.

PEKMB evolving to squamous cell carcinoma was made and the lesion was excised with wide margins.

\section{Conclusions}

PEKMB is a rare, nonvenereal, premalignant genital dermatosis. It was first described by Lortat-Jacob and Civatte in 1961, and until now approximately 20 cases have been reported in the literature. It occurs in older men, most of whom were circumcised late in life. It presents as a keratotic plaque with thick, white, mica-like silvery scales and keratotic horny masses on the glans. Ulcerations and fissuring may develop. The etiology of PEKMB is unknown and it progresses through 4 different stages: plaque, tumor, verrucous carcinoma, and later squamous cell carcinoma [1].

Although PEKMB has uncertain malignant potential, it can sometimes progress to verrucous carcinoma and squamous cell carcinoma and therefore an early biopsy and close follow-up are warranted [2]. Histological examination of these lesions reveals acanthosis, hyperkeratosis, and pseudoepitheliomatous hyperplasia with no cytological atypia.

Treatment depends on severity and may range from topical treatment with 5-flurouracil cream, cryotherapy, shaving biopsy plus electrocoagulation, or triamcinolone acetonide cream $(0.1 \%)$ to excision with wide margins. However, treatment is not always satisfactory and relapses are frequent.

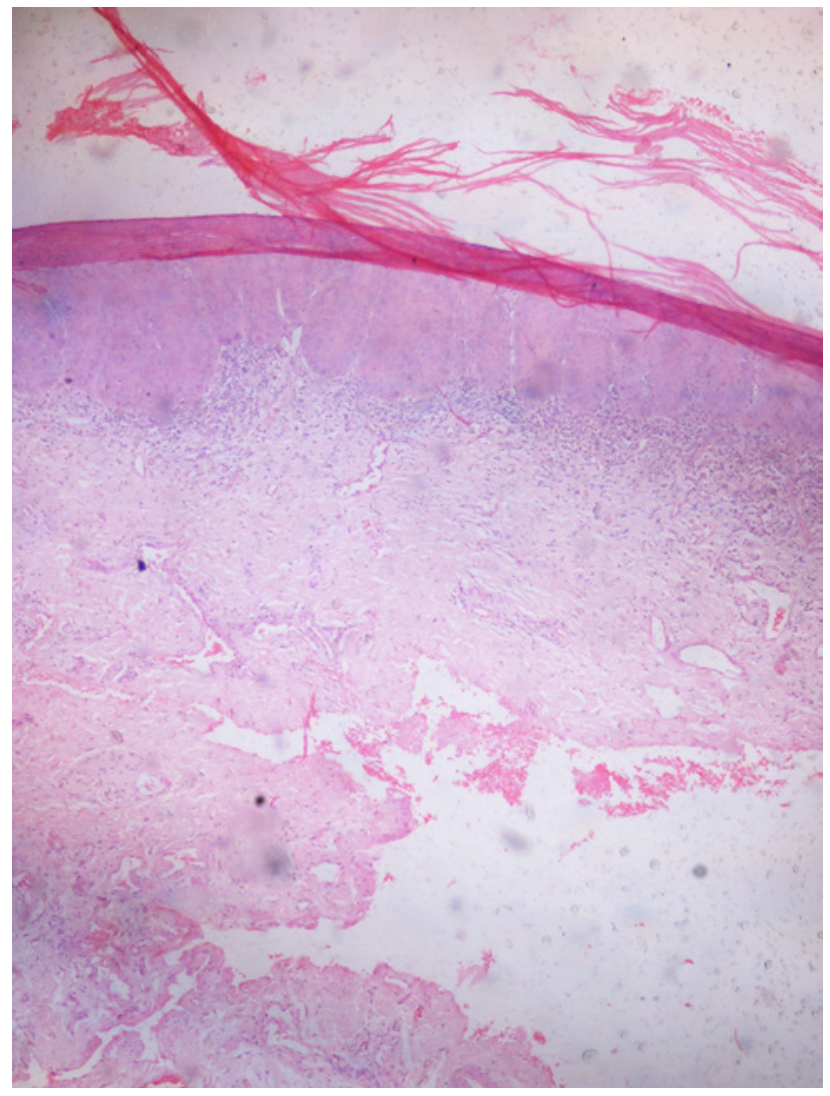

\section{References}

1. Krunic AL, Djerdj K, Starcevic-Bozovic A, et al. Pseudoepitheliomatous, keratotic and micaceous balanitis: case report and review of the literature. Urol Int. 1996;56(2):125-128.

2. Perry D, Lynch PJ, Fazel N. Pseudoepitheliomatous, keratotic, and micaceous balanitis: case report and review of the literature. Dermatol Nurs. 2008;20(2):117-120. 